\title{
Oriented immobilization and electron transfer to the cytochrome c oxidase
}

\author{
Christoph Nowak • Denise Schach • Jens Gebert • Marc Grosserueschkamp • \\ Robert B. Gennis • Shelagh Ferguson-Miller • Wolfgang Knoll • Dieter Walz • \\ Renate L. C. Naumann
}

Received: 18 November 2009/Revised: 12 February 2010/Accepted: 12 February 2010/Published online: 13 March 2010

(C) The Author(s) 2010. This article is published with open access at Springerlink.com

\begin{abstract}
Direct electron transfer to cytochrome c oxidase $(\mathrm{CcO})$ is investigated as a function of packing density of the surface layer. This is varied by the surface concentration of chelator molecules when the enzyme is immobilized on the electrode using the his-tag technology. Chelator molecules
\end{abstract}

In honor of Dr. Friedrich G. K. Baucke on the occasion of his 80th birthday

Electronic supplementary material The online version of this article (doi:10.1007/s10008-010-1032-x) contains supplementary material, which is available to authorized users.

C. Nowak · D. Schach · J. Gebert • M. Grosserueschkamp •

R. L. C. Naumann $(\bowtie)$

Max Planck Institute for Polymer Research,

Ackermannweg 10,

55128 Mainz, Germany

e-mail: naumannr@mpip-mainz.mpg.de

R. B. Gennis

Department of Biochemistry, University of Illinois,

600 South Mathews Street,

Urbana, IL 61801, USA

\section{S. Ferguson-Miller}

Michigan State University Biochemistry and Molecular Biology,

East Lansing, MI, USA

C. Nowak · D. Schach · J. Gebert • M. Grosserueschkamp •

W. Knoll $\cdot$ R. L. C. Naumann

Austrian Institute of Technology GmbH -AIT,

Donau-City Str. 1,

1220 Vienna, Austria

D. Walz

Biozentrum, University of Basel,

Basel, Switzerland

Present Address:

D. Walz

Lerchenstrasse 21,

4059 Basel, Switzerland with a terminal nitrilotriacetic acid group are synthesized ex situ in contrast to in situ synthesis used in a previous work. Self-assembled monolayers of the chelator mixed at different mole fractions with a dilution molecule are prepared to bind the $\mathrm{CcO}$ after complex formation with $\mathrm{Ni}^{2+}$ ions. The $\mathrm{CcO}$, which is immobilized in the solubilized form, is then reconstituted into a proteintethered bilayer lipid membrane (ptBLM). Varying the mixing ratio of chelator to dilution molecules enabled us to control the packing density of $\mathrm{CcO}$ residing in the ptBLM. Subtle differences in the architecture of the protein/lipid layers revealed by surface-enhanced IR absorption spectroscopy are considered to be essential for an effective electron transfer. Cyclic voltammograms are measured under anaerobic conditions at different scan rates and analyzed by means of a model which describes the transfer of four electrons to $\mathrm{CcO}$ in the ptBLM. The rate constants thus obtained show a marked dependence on the packing density.

\section{Introduction}

Electrochemistry had proved to be valuable for the investigation of electron transfer (ET) to proteins [1-3]. For this purpose, proteins were either adsorbed to gold or carbon electrodes or covalently attached via specific linker molecules [4]. Linkers offer the advantage of a predetermined orientation of the bound protein, which is important for an effective ET. The his-tag technology seems to be promising in this context [5]. We had introduced this technique into the spectroelectrochemistry of membrane proteins such as the cytochrome c oxidase (CcO) [6]. Lipid molecules could be reconstituted around the protein to form a protein-tethered bilayer lipid membrane (ptBLM; Fig. 1). Direct ET into the redox centers of the protein was 


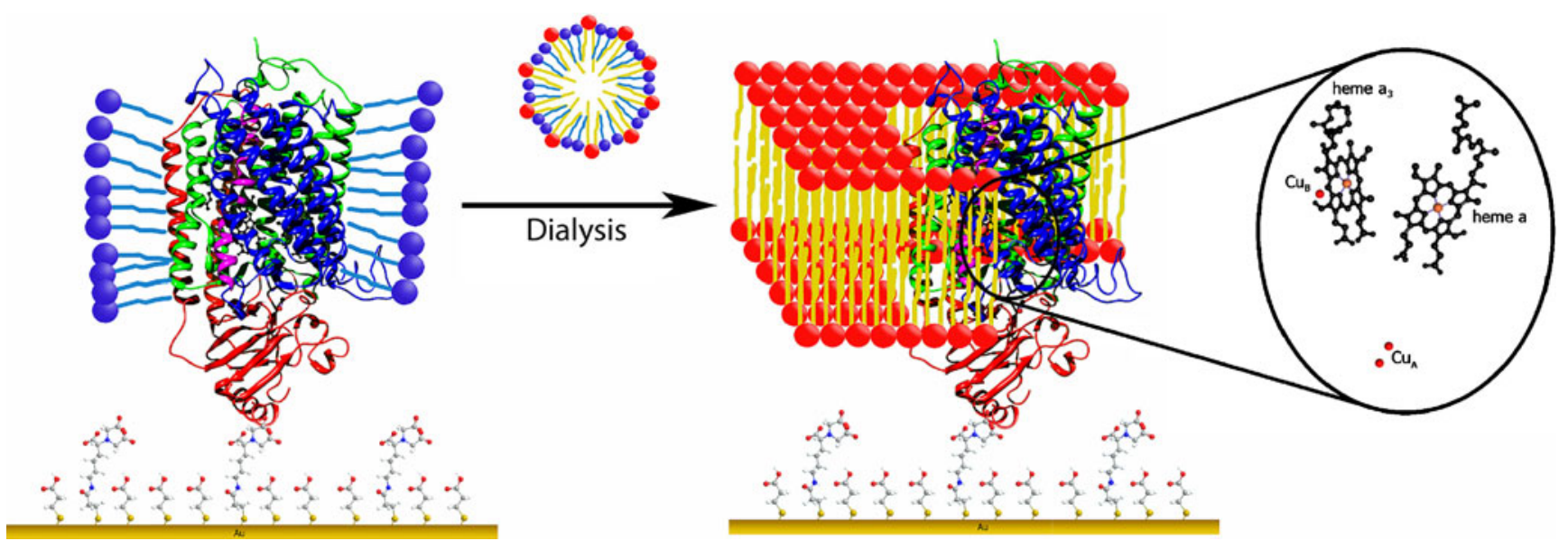

Fig. 1 Schematics of the reconstitution of the $\mathrm{CcO}$ immobilized by the his-tag attached to subunit II into a ptBLM by in situ dialysis. In this orientation, the $\mathrm{CcO}$ receives electrons from the electrode via the first electron acceptor, $\mathrm{Cu}_{\mathrm{A}}$. In its native environment, i.e., the inner mitochondrial membrane, $\mathrm{CcO}$ receives electrons from reduced cytochrome $\mathrm{c}$, from which they are transferred to $\mathrm{Cu}_{\mathrm{A}}$ and further on to the other centers heme $\mathrm{a}$, heme $\mathrm{a}_{3}$, and $\mathrm{Cu}_{\mathrm{B}}$ in this sequence investigated, provided the protein was immobilized in an adequate orientation [7].

Orientation, however, is not sufficient to ensure an effective ET. Packing density of the proteins turned out to be another crucial parameter [8]. Packing density was controlled by the surface concentration of chelator molecules, with a terminal nitrilotriacetic acid group (NTA; Fig. 2). They were prepared in situ from a surface-bound active ester (dithiobis( $\mathrm{N}$-succinimidyl propionate) (DTSP)) as described in our previous work [7]. In situ synthesis, however, allows insufficient control over the surface concentration. Therefore, in the present work, we proceeded to replace the in situ by an ex situ synthesis to form the chelator, dithiobis(nitriloacetic acid butylamidyl propionate (DTNTA), according to the reaction equation given in Fig. 2

Self-assembled monolayers were then formed from solutions of DTNTA mixed with dithiodipropionic acid, dithiobis (propionic acid) (DTP), the precursor of DTNTA, in preselected mole fractions. The surface concentration of DTNTA could thus be controlled more effectively compared to previous studies. Cytochrome c oxidase with the his-tag attached to subunit II was immobilized and reconstituted into a ptBLM. The kinetics of ET to the redox centers was probed as a function of packing density employing cyclic voltammetry. To analyze the data, electron transfer was modeled using the four-electron transfer model developed recently [9]. Moreover, IR spectroscopy revealed subtle differences in the architecture of the protein/lipid layers that could be essential for an effective ET.

\section{Materials and methods}

Dithiobis (nitriloacetic acid butylamidyl propionate) (DTNTA) $\mathrm{N}$-(5-amino-1-carboxypentyl) iminoacetic acid (ANTA; $5.63 \mathrm{mmol} ; 1.47 \mathrm{~g}$ ) in 20-ml dry DMF and $2 \mathrm{ml}$ triethylamine has been stirred at $80{ }^{\circ} \mathrm{C}$ till ANTA was dissolved. DTSP (1.01 g; $2.56 \mathrm{mmol})$ solved in $10 \mathrm{ml}$ dry DMF was added to the solution and kept stirring at $80^{\circ} \mathrm{C}$ for $24 \mathrm{~h}$. After removing the solvent under reduced pressure, the resulting mixture was filtered with diethylether through silica gel. After removing the solvent, the product was purified by flash- $\mathrm{SiO}_{2}$ column chromatography (methanol/acetone $=1: 1$ ) with $428 \mathrm{mg}(24 \%)$ yield of a brown viscous oil. ${ }^{1} \mathrm{H}$ NMR

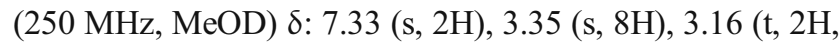
$J=7.5 \mathrm{~Hz}), 2.96(\mathrm{t}, 4 \mathrm{H}, J=7.5 \mathrm{~Hz}), 2.81(\mathrm{~m}, 2 \mathrm{H}), 2.73(\mathrm{~m}$, $2 \mathrm{H}), 2.65$ (t, $4 \mathrm{H}, J=7.5 \mathrm{~Hz}), 1.65-1.45(\mathrm{~m}, 12 \mathrm{H}) \mathrm{ppm}$. [10] C (100 MHz, MeOD) d: 179.79, 175.26, 173.40, 70.91,
Fig. 2 Reaction scheme of the ex situ formation of the chelator molecule, DTNTA from the precursors DTSP and ANTA

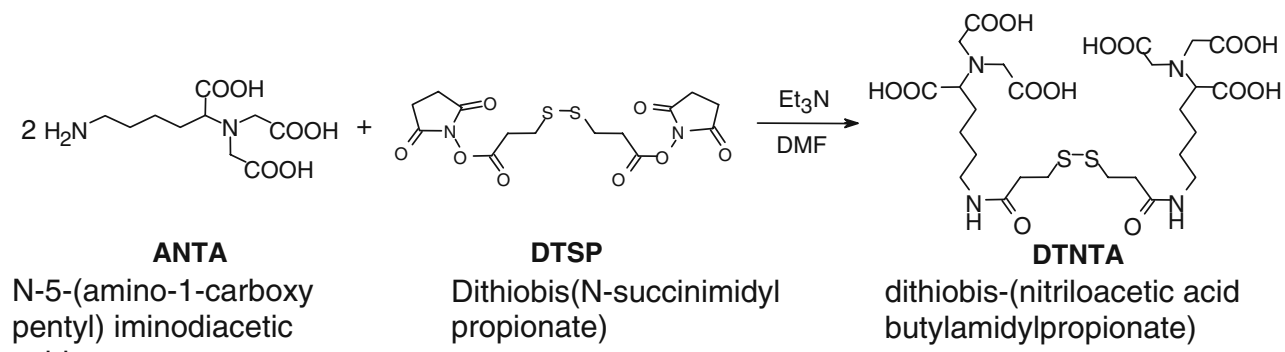

dithiobis-(nitriloacetic acid butylamidylpropionate) 
58.24, 42.12, 36.84, 31.34, 29.87, 28.52, 26.71, 26.64 ppm. Mass spectrum (ESI): Calculated for $\mathrm{C}_{26} \mathrm{H}_{42} \mathrm{~N}_{4} \mathrm{O}_{14} \mathrm{~S}_{2}$ : m/e 698.76. Found: $m / e$ 699.27.

Preparation of the two-layer gold surface used for the IR measurements It was done as previously described [11, 12]. Briefly, the polished silicon Attenuated Total Reflection (ATR) crystal was immersed for $1 \mathrm{~h}$ into $10 \%$ solution of (mercaptopropyl) triethoxysilane (MPTES). After rinsing with ethanol and ultrasonic cleaning with methanol, the samples were dried in air and annealed at $100{ }^{\circ} \mathrm{C}$ for $1 \mathrm{~h}$. After cooling down to room temperature, the samples are immersed in water for $10 \mathrm{~min}$ and dried under a stream of nitrogen. Then a 30-nm gold film was deposited by electrothermal evaporation onto the ATR crystal. Gold nanoparticles were grown onto the gold film by immersion into $50 \mathrm{ml}$ of an aqueous solution of hydroxylamine hydrochloride $\left(\mathrm{NH}_{2} \mathrm{OH} \mathrm{HCl} ; 0.4 \mathrm{mM}\right)$, to which $500-\mu \mathrm{l}$ portions of an aqueous solution of gold(III) chloride hydrate $(0.3 \mathrm{mM})$ were added five times with a delay time of $2 \mathrm{~min}$. After that the samples were rinsed with water and dried in a stream of nitrogen.

Immobilization of the protein It was performed as previously described $[6,7,13]$. Briefly, $\mathrm{CcO}$ from Rhodobacter sphaeroides with a his-tag engineered to the $\mathrm{C}$ terminus of subunit II was expressed and purified according to Mitchell and Gennis [10]. Either template-stripped gold electrodes or the above-mentioned ATR crystals with a two-layer gold surface were immersed for $24 \mathrm{~h}$ in a solution in dry DMSO of DTNTA and DTP mixed at mole ratios varying from 0.1 to 0.4 (total concentration $2 \mathrm{mg} / \mathrm{ml}$ ). After rinsing with DMSO, followed by deionized (DI) water $\mathrm{pH}=5$, the slides were immersed for $30 \mathrm{~min}$ in $40 \mathrm{mM} \mathrm{NiSO}{ }_{4}$ in acetate buffer $(50 \mathrm{mM}, \mathrm{pH}=5.5)$ followed by thorough rinsing with DI water $\mathrm{pH}=5$ to remove the excess $\mathrm{NiSO}_{4}$. Then, $\mathrm{CcO}$ dissolved in dodecyl $\beta$-D-maltoside (DDM) phosphate buffer $\left(\mathrm{K}_{2} \mathrm{HPO}_{4}\right.$ $0.1 \mathrm{M}, \mathrm{KCl} 0.05 \mathrm{M}, \mathrm{pH}=8,0.1 \% \mathrm{DDM}$ ) was adsorbed to the NTA-functionalized surface at a final concentration of $10 \mathrm{nM}$. After 4-h adsorption time, the cell was rinsed with DDM phosphate buffer. Then, a DiPhyPC solution $(40 \mu \mathrm{M})$ in DDM-phosphate buffer was added. Dialysis was performed by adding Biobeads (Bio-Rad Laboratories $\mathrm{GmbH}$, Munich, Germany) to the lipid-detergent solution.

Spectroelectrochemical measurements The spectroelectrochemical cell was mounted on top of a trapezoid silicon ATR crystal required for a single reflection in the ATR spectroscopy mode [12]. The IR beam of the FTIR spectrometer (VERTEX 70 FTIR spectrometer, from Bruker, Karlsruhe) was coupled into the prism at an angle of incidence $\Theta=60^{\circ}$. The total reflected beam IR intensity was measured with a photovoltaic mercury cadmium telluride detector. For potentiostatic titrations, the ATRFTIR setup was equipped with a function generator which triggered the potentiostat of the Autolab (PGSTAT302; Eco Chemie, B.V., Utrecht, Netherlands) as well as the spectrometer. Measurements under anaerobic conditions were performed in a buffer solution flushed with $\mathrm{Ar}$ containing $\mathrm{K}_{2} \mathrm{HPO}_{4}(0.05 \mathrm{M}), \mathrm{KCl}(0.1 \mathrm{M}), \mathrm{pH}=8$, and the oxygen trap consisting of glucose $(0.3 \% \mathrm{w} / \mathrm{w})$, glucose oxidase $(75 \mu \mathrm{g} / \mathrm{ml})$, and catalase $(12.5 \mu \mathrm{g} / \mathrm{ml})$. Electrochemical measurements were taken in a three-electrode configuration with gold as the working electrode, a $\mathrm{Ag}$ | $\mathrm{AgCl}, \mathrm{KCl}_{\text {sat }}$ reference and a platinum wire as the counter electrode. All electrode potentials are quoted vs Standard Hydrogen Electrode (SHE).

Spectra were analyzed using the software package OPUS 6 (Bruker Optics GmbH; Ettlingen). Spectra of the protein were corrected with respect to the substrate in buffer solution at the appropriate potential. In addition, the band at $1,643 \mathrm{~cm}^{-1}$ due to water incompensation was subtracted from the respective spectrum of the protein. A linear baseline correction was performed between 2,500 and $1,300 \mathrm{~cm}^{-1}$.

Simulation of cyclic voltammograms and parameter fitting We have recently presented a model describing the transfer of electrons to a protein complex adsorbed to an electrode containing four redox centers. The model is based on two possible mechanisms [9]. In the first mechanism referred to as "sequential ET," the first center can take up electrons from the electrode, while the other centers exchange electrons with their neighbors in sequence, as shown in Fig. 3a. If applied to $\mathrm{CcO}$, the centers $1,2,3$, and 4 represent $\mathrm{Cu}_{\mathrm{A}}$, heme a, heme $\mathrm{a}_{3}$, and $\mathrm{Cu}_{\mathrm{B}}$, respectively. This mechanism, thus, reflects the pathway of electrons which is generally accepted to be followed in $\mathrm{CcO}$ when it receives electrons from its genuine donor, i.e., cytochrome c (see Fig. 1). In the second mechanism referred to as "independent ET," all centers can take up electrons directly from the electrode but do not exchange electrons with their neighbors (Fig. 3b). In this case, no unambiguous assignment of centers $1-4$ to the redox centers in $\mathrm{CcO}$ is possible. The mathematical description of the model can be found in the Electronic Supplementary Material.

To simulate cyclic voltammograms, the model was transformed into an electrical network representation, and the network simulation program Spice could then be used for integration [14]. Spice has been introduced previously to model bioelectrochemical processes across membranes [15]. It is in the public domain and available for various computer systems. We routinely use MacSpice (version 3f5) on Mac computers with OS X (versions 10.4.x). The fitting of parameter values of the model to experimental data was performed by means of the program MODFIT [16], which was implemented in the control structure of Spice. 
Fig. 3 Kinetic schemes for the models of sequential (a) and independent electron transfer (b) to a complex with four redox centers. The various redox states (oxidized or reduced) of the centers arising upon electron transfer are considered as different states of the complex, which are numbered sequentially. Vertical transitions between states represent electron transfer between the electrode and a center (electron uptake), which are governed by the electrochemical rate constants $k_{e, i}$. Horizontal transitions represent transfer between two centers (electron exchange), which are described by the forward rate constants $k_{i, i+1}$. All transitions are reversible but, for graphical reasons, are represented here only by single arrows indicating the positive direction of transition flows. For further details, see [9] and the Electronic Supplementary Material

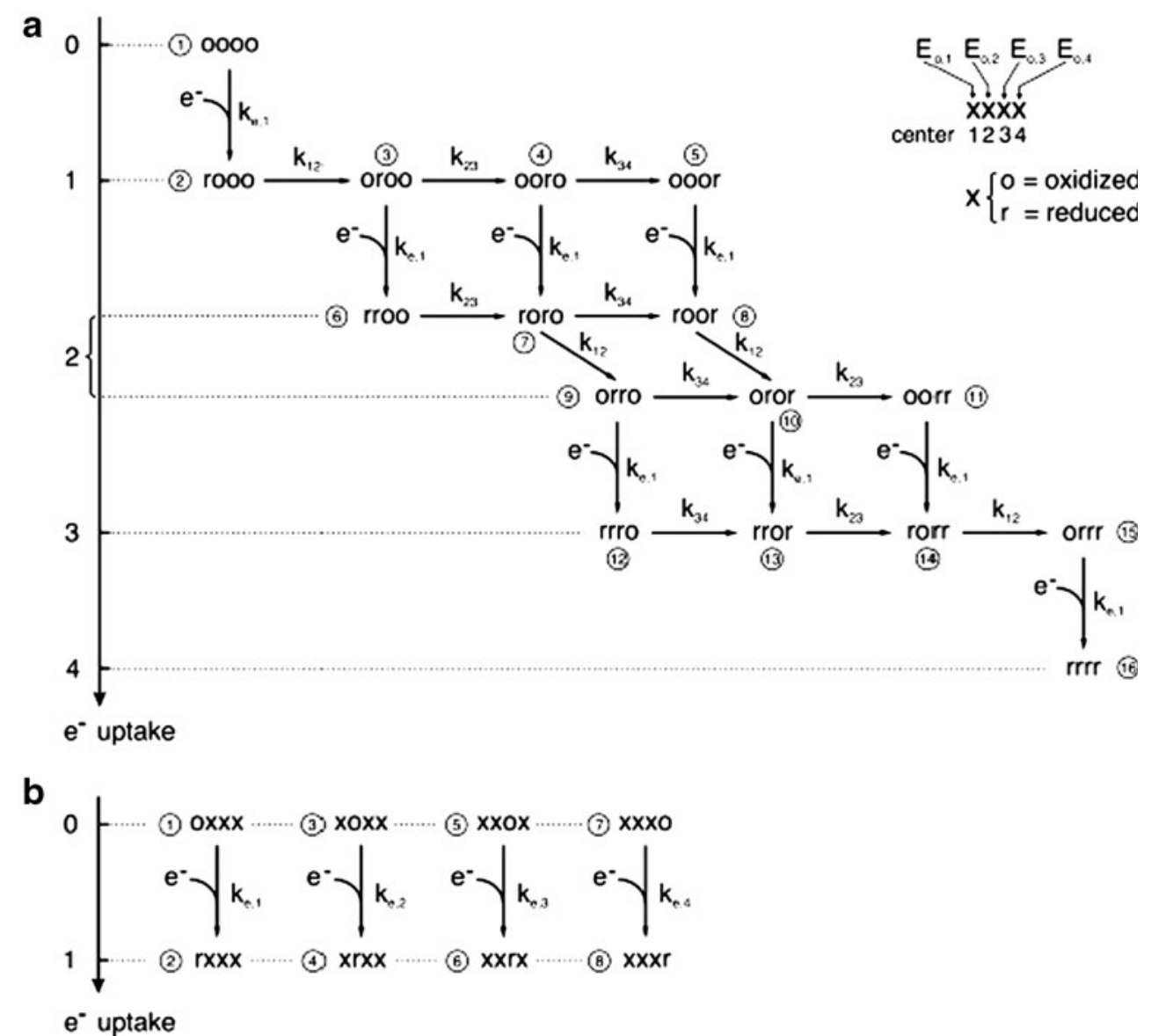

For further information on this routine and details of the MacSpice program, contact D. Walz (dieter.walz@unibas.ch).

\section{Results and discussion}

Characterization of the surface layer by impedance spectroscopy

The packing density was controlled by the surface concentration of chelator molecules (DTNTA). This was achieved by binding the $\mathrm{CcO}$ to self-assembled monolayers of DTNTA mixed with DTP at different mole fractions. Thereafter, the $\mathrm{CcO}$ was reconstituted into a ptBLM. The quality of membrane formation was verified by electrochemical impedance spectroscopy. Capacitance and resistance of the layer before and after membrane formation is shown in Fig. 4 for mole fractions of 0.1, 0.2, and 0.3. High resistances of the order of megaohm square centimeters indicate good electrical sealing properties. The decrease of the capacitance values indicate that detergent and water molecules residing between the proteins are replaced by lipid bilayer patches, considering the dielectric constant of lipids (2.2) is smaller than that of water (80) and proteins. The lowest capacitance $\left(14 \mu \mathrm{F} \mathrm{cm}{ }^{-2}\right)$ was obtained at a mole fraction of 0.2 . This is high compared to $7 \mu \mathrm{F} \mathrm{cm} \mathrm{cm}^{-2}$ measured in earlier studies indicating a high surface coverage by the protein [7]. A pure lipid bilayer membrane would have a capacitance as low as $0.5 \mu \mathrm{F} \mathrm{cm}{ }^{-2}$.

Characterization of the surface layer by surface-enhanced IR absorption spectroscopy (SEIRAS)

SEIRAS had been used previously to investigate the oriented immobilization of $\mathrm{CcO}$ molecules onto an in situ functionalized surface [17]. The same technique with slight modifications was used to investigate the oriented immobilization in the case of the ex situ functionalized surface [18]. Modifications concern different preparations of the gold film [11] and different orientations of the $\mathrm{CcO}$. $\mathrm{CcO}$ in the orientation with the his-tag engineered to subunit I was used previously [17].

In the present study, $\mathrm{CcO}$ with the his-tag attached to subunit II was immobilized on the two-layer gold film on the ATR crystal of the IR spectrometer, modified with mixtures of DTNTA/DTP at different mole fractions. SEIRA difference spectra were measured in the ATR configuration as a function of absorption time. The DTNTA/DTP-modified two-layer gold electrode was used as the reference. The results are shown in Fig. 5 compared 

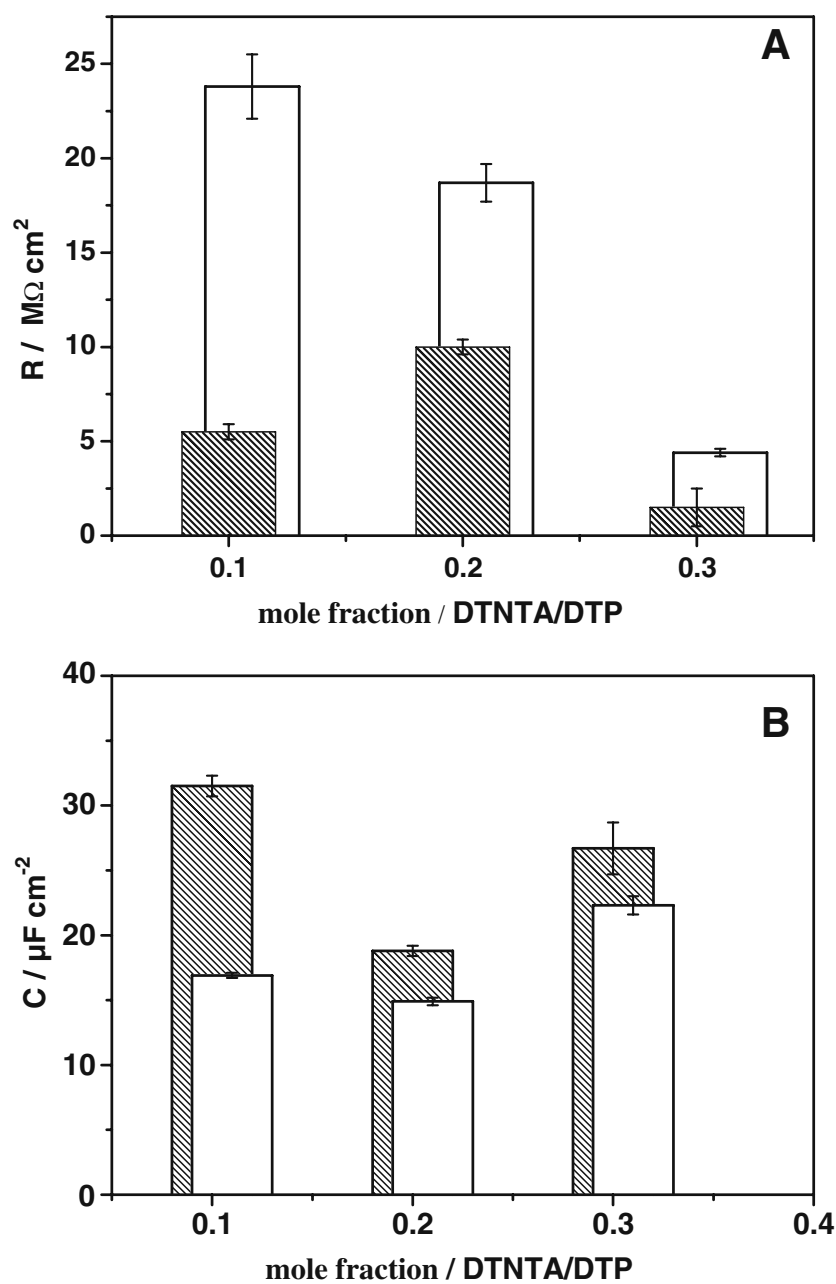

Fig. 4 Resistance (a) and capacitance (b) obtained from impedance spectra before (shaded bar) and after (open bar) reconstitution into a ptBLM, obtained on a TSG electrode ex situ functionalized with mixtures of DTNTA/DTP at different mole fractions. Mean values and standard deviations of three experiments

to respective spectra measured on the in situ functionalized surface.

Figure 5 shows the difference spectra with positive bands appearing at 1,641, 1,524, 1,442, 1,360, and $1304 \mathrm{~cm}^{-1}$. The first two bands assigned to the amide I and the amide II modes of the protein backbone vibrations were slightly shifted vs our previous finding, 1,658 and $1,571 \mathrm{~cm}^{-1}$, respectively [17]. This is probably due to the different orientations of the $\mathrm{CcO}$. The band at $1,304 \mathrm{~cm}^{-1}$ could be assigned to the amide III mode of $\mathrm{CcO}$ [19]. The band at 1,442 corresponds to a band at $1,440 \mathrm{~cm}^{-1}$ found earlier. This one and the band at $1,360 \mathrm{~cm}^{-1}$ account for the symmetric stretching vibrations of the carboxylate group of DTNTA, the chelator for the $\mathrm{Ni}^{2+}$ ion $[17,20]$. The most striking difference between the in situ (Fig. 5a) and ex situ (Fig. 5b-e) coupled DTNTA modified surface is the difference in the amplitude of the absorbance of the amide
I band. The absorbance in the ex situ case is by a factor of 2 to 5 smaller than the in situ case. A lower surface concentration can be excluded as deduced from the surface coverage obtained from the electrochemical data, at least at the 0.2 mole fraction. Hence, the relatively low absorbance can only be explained in terms of a larger distance of the $\mathrm{CcO}$ molecules from the surface of the ATR crystal. The intensity of SEIRA spectra is known to decrease exponentially as a function of the electric field extending in the solution. This is supported by the amplitude of the band at $1,442 \mathrm{~cm}^{-1}$, growing relatively more rapidly with $\mathrm{CcO}$ binding. A possible explanation is a conformational change in the DTNTA/DTP monolayer. In the case of the ex situ formation of DTNTA molecules, the molecules seem to have greater flexibility to bind his-tags. This could be due to a more extended conformation than in the case of DTNTA formed in situ. Moreover, at the mole fraction 0.2, a band at $1,598 \mathrm{~cm}^{-1}$ shows up that is not present in the case of the other mixing ratios. This band accounts for the amide I vibration of $\beta$-sheets, whereas the band at $1,641 \mathrm{~cm}^{-1}$ is characteristic for the $\alpha$-helices in the protein backbone of $\mathrm{CcO}$. $\mathrm{Cu}_{\mathrm{A}}$, the first electron acceptor, is located in the region of the $\beta$-sheets, contrary to the remaining redox centers, which are found in the helical region. We conclude that even though the packing density of proteins seems to be higher as seen from the impedance and cyclic voltammetry data (see below), $\beta$-sheets may unfold from the $\alpha$ helices to facilitate $\mathrm{ET}$ to $\mathrm{Cu}_{\mathrm{A}}$, particularly at the mole fraction 0.2 .

While the spectra of the solubilized $\mathrm{CcO}$ correspond by and large to our previous findings (Fig. 5), the difference spectrum after formation of the lipid membrane is markedly different (Fig. 6a). Band assignments are summarized in Table 1. Previously, a large negative band at $3,500 \mathrm{~cm}^{-1}$ accounted for water molecules displaced from the surface. By contrast, a positive band at $3,455 \mathrm{~cm}^{-1}$ appeared that we consider as water molecules accumulating in the submembrane space. A negative $\mathrm{OH}$ band at $3,691 \mathrm{~cm}^{-1}$ seems to indicate other water molecules displaced from the space between proteins. Positive bands between 2,852 and $2,961 \mathrm{~cm}^{-1}$ were considered earlier only in terms of phospholipids accumulating between proteins. By contrast, small negative bands at 2,855 and $2,929 \mathrm{~cm}^{-1}$ appeared in the present study. They may be due to $\mathrm{CH}$ stretching vibrations of both the detergent (DDM) and lipid molecules. If the lipids are inserted at a larger distance from the surface while detergents are removed particularly from the submembrane space, the overall response is negative. Moreover, positive and negative bands were observed in the amide I region, which were not observed in [7], see Fig. $6 \mathrm{~b}$ for an expanded scale. That means the protein backbone may rearrange as lipids are inserted in between. From this, we conclude a more extensive rearrangement of 

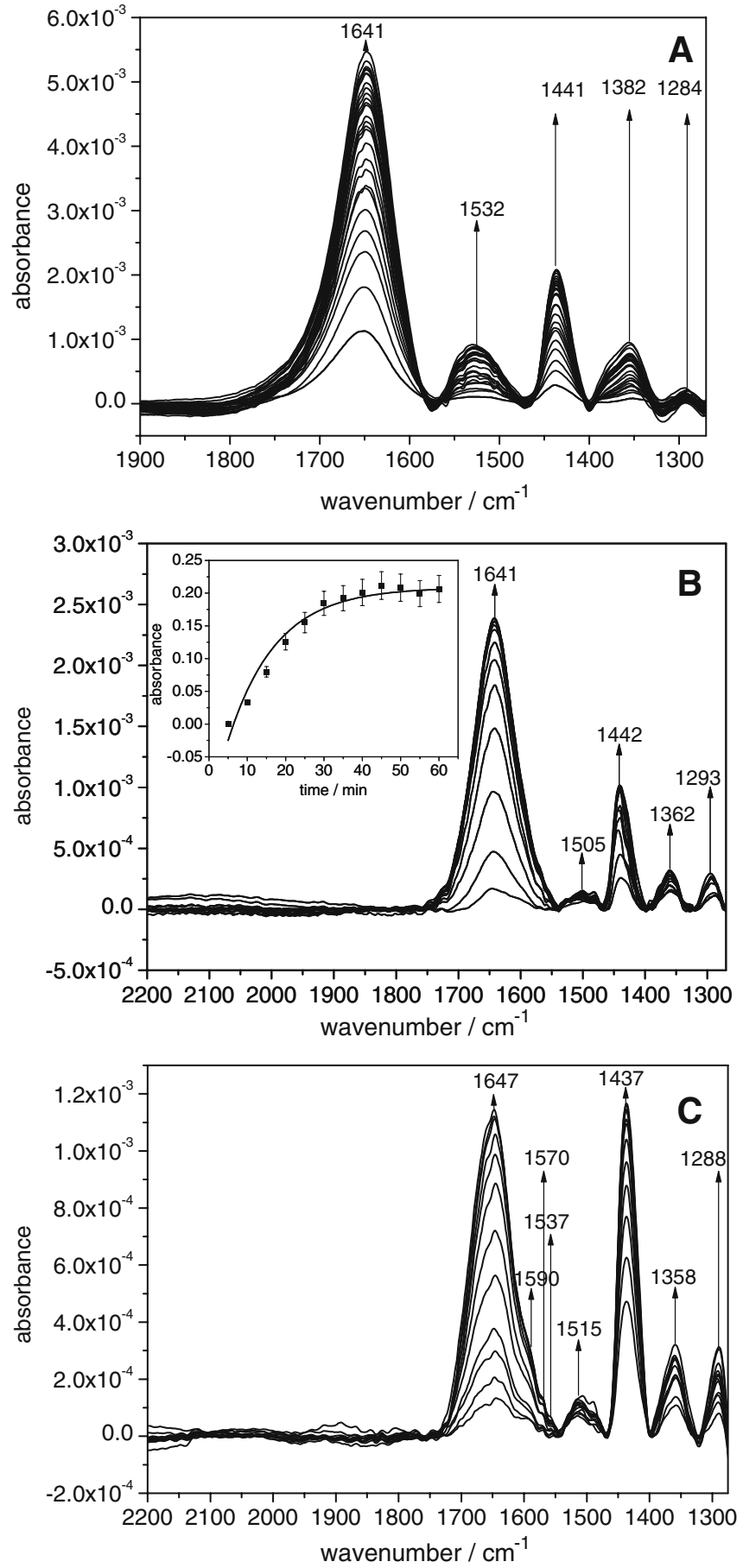

Fig. 5 Immobilization of the $\mathrm{CcO}$ solubilized in DDM followed by surface-enhanced ATR-IR-Spectroscopy. Difference spectra were taken every $5 \mathrm{~min}$. a The two-layer gold surface was modified with DTSP/DTP, while DTNTA was formed in situ. $\mathbf{b}-\mathbf{e}$ The two-layer gold

the entire layer structure than in the case of the in situ functionalized surface.

Different packing densities most likely account for some of the differences between the investigations, particularly concerning [7]. A larger flexibility of the entire
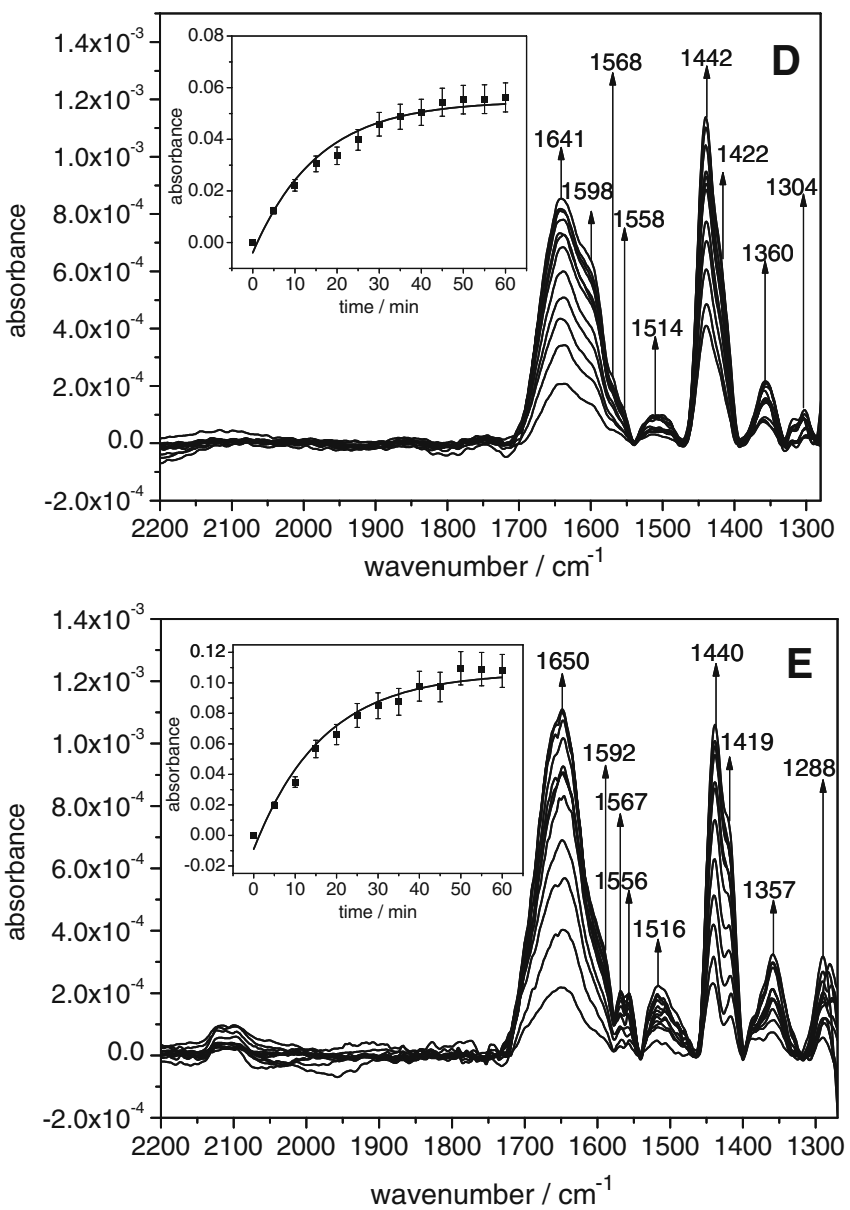

surface was modified with mixtures of DTNTA/DTP at a mole fraction of $0.4(\mathbf{b}), 0.3(\mathbf{c}), 0.2(\mathbf{d})$, and 0.1 (e). The modified surfaces were used as the reference. The insets show the amplitude of the band at $1,641 \mathrm{~cm}^{-1}$ plotted as a function of time

DTNTA-CcO architecture is assumed in the case of the DTNTA/DTP-modified surface. The linker seems to extend into the aqueous phase providing not only a larger submembrane space but also a greater mobility of the bound proteins. 

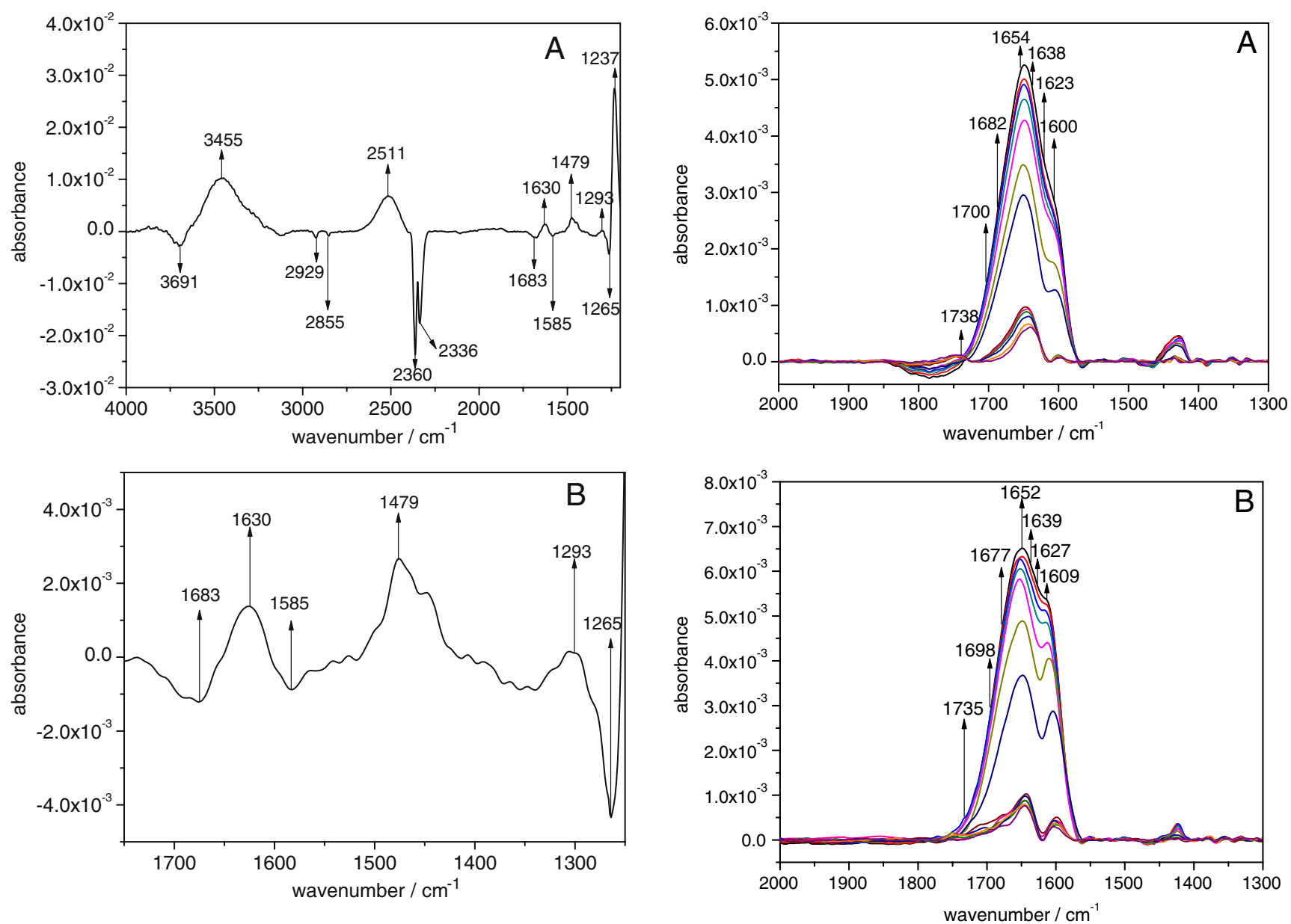

Fig. 6 Reconstitution of the $\mathrm{CcO}$ immobilized by the his-tag attached to subunit II into a protein-tethered bilayer lipid membrane (ptBLM) by in situ dialysis followed by surface-enhanced ATR-IRSpectroscopy. a Difference spectra before and after in situ dialysis in the range $1230-4000 \mathrm{~cm}^{-1}$. (b) Difference spectra before and after in situ dialysis in the range $1,250-1,800 \mathrm{~cm}^{-1}$ in an expanded scale

Fig. 7 Potentiometric titration of $\mathrm{CcO}$ by surface-enhanced ATR-IRSpectroscopy. Difference spectra reduced, fully oxidized for activated $\mathrm{CcO}$ immobilized via his-tag on subunit II (cf. Fig. 1), a on an in situ functionalized surface, $\mathbf{b}$ on an ex situ functionalized surface. Potential applied was $900 \mathrm{mV}$ vs SHE for the fully oxidized state and varied from 500 to $-700 \mathrm{mV}$ in $100-\mathrm{mV}$ steps for reduced states (bottom to top)

Table 1 Band assignment of the difference spectrum (Fig. 6) after insertion of lipids to form the protein-tethered lipid bilayer membrane

\begin{tabular}{|c|c|c|}
\hline Wave number $/ \mathrm{cm}^{-1}$ & Group & Comment \\
\hline 1237 & $\mathrm{OH}$ deformation vibration & $\mathrm{H}_{2} \mathrm{O}$ and $\mathrm{POOH}$ \\
\hline $\begin{array}{l}1265 \\
1293\end{array}$ & Amide III & $1,299 \mathrm{~cm}^{-1}$ \\
\hline $\begin{array}{l}1479 \\
1585\end{array}$ & Amide II & CcO solubilized: $1,550 \mathrm{~cm}^{-1}$ [7], $1,532 \mathrm{~cm}^{-1}$ in Fig. 6 \\
\hline $\begin{array}{l}1630 \\
1683\end{array}$ & Amide I & CcO solubilized: $1,658 \mathrm{~cm}^{-1}$ [7], 1,641 $\mathrm{cm}^{-1}$ in Fig. 6 \\
\hline $\begin{array}{l}2336 \\
2360\end{array}$ & $\mathrm{CO}_{2}$ & measurement in the presence of air \\
\hline 2511 & & \\
\hline $\begin{array}{l}2855 \\
2929\end{array}$ & $\mathrm{CH}$ valence vibration & DDM and phospholipids (DPhyPC) \\
\hline $\begin{array}{l}3455 \\
3691\end{array}$ & $\begin{array}{l}\mathrm{OH} \text { vibration in hydrogen bonds } \\
\text { Valence vibration of free } \mathrm{OH}\end{array}$ & $\mathrm{H}$-bonds primarily in sp3-hybridized atoms like $\mathrm{O}, \mathrm{N}$, and $\mathrm{F}$ \\
\hline
\end{tabular}

The reference spectrum was taken from the $\mathrm{CcO}$ solubilized in the DDM containing buffer solution and immobilized on the DTNTA/DTP modified surface (mole fraction 0.2) 
Finally, a potentiometric titration was performed employing the ptBLM prepared under optimized conditions of ex situ formed DTNTA compared to the one formed in situ. Figure 7 shows the difference spectra taken at different potentials in both cases. Bands in the region of the amide I band were analyzed by plotting their peak absorbance $A$ vs the applied potential $E$ and fitting the data to the sigmoid function

$A=\frac{\Delta A_{\text {ro }}}{1+\exp \left[\left(E-E_{\mathrm{ip}}\right) / \varphi\right]}+A_{0}$

where $\Delta A_{\text {ro }}$ denotes the absorbance difference between the fully reduced and fully oxidized forms, while the term $A_{0}$ accounts for a possible deviation from zero. $E_{\mathrm{ip}}$ is the potential of the inflection point, which reflects the midpoint potential $E_{\mathrm{m}}$ of the redox center, and $\varphi$ is a scaling factor. Ideally, $A_{0}=0, \varphi=R T / F \approx 26 \mathrm{mV}$, and $E_{\mathrm{ip}}=E_{\mathrm{m}}$. Such sigmoid functions of the absorbance are a clear indication of
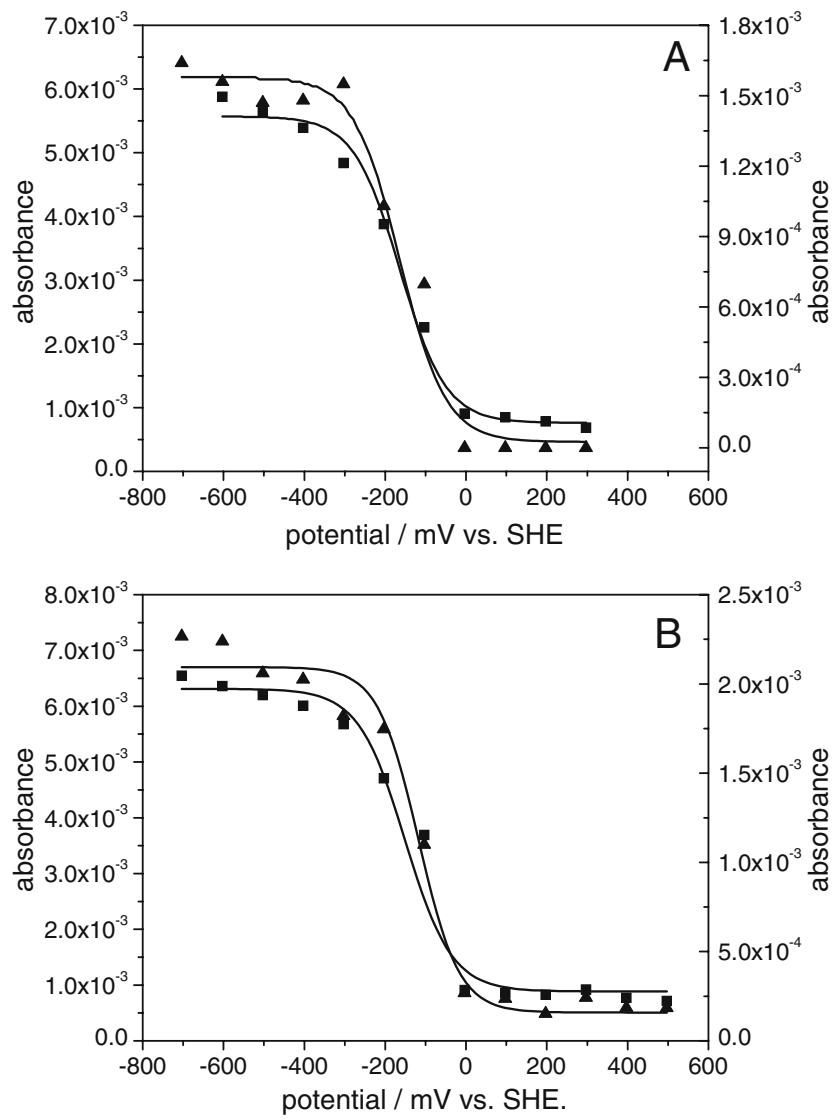

Fig. 8 Dependence of peak absorbance $A$ on applied potential $E$. Bands taken from spectra given in Fig. 7 of the activated $\mathrm{CcO}$ immobilized $\mathbf{a}$ on an in situ functionalized surface and $\mathbf{b}$ on an ex situ functionalized surface, at wave numbers 1,651 (squares, right-hand scale) and 1,605 $\mathrm{cm}^{-1}$ (triangles, left-hand scale) assigned to heme $\mathrm{a}_{3}$ and $\mathrm{Cu}_{\mathrm{A}}$, respectively. The sigmoid curves represent Eq. 1 fitted to the data; the pertinent values of $E_{\text {ip }}$ are -164 and $-163 \mathrm{mV}(\mathbf{a}),-117$ and $-150 \mathrm{mV}$ (b) for heme $\mathrm{a}_{3}$ and $\mathrm{Cu}_{\mathrm{A}}$, respectively

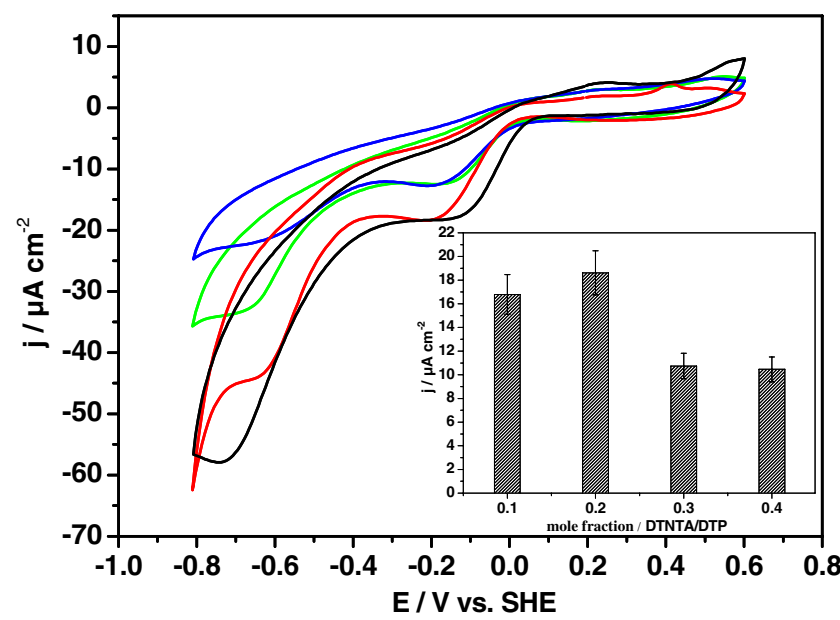

Fig. $9 \mathrm{CVs}$ of the $\mathrm{CcO}$ immobilized on an ex situ functionalized surface via his-tag attached to subunit II and reconstituted into a ptBLM. a Under aerobic conditions, the electrode was modified with mixtures of DTNTA/DTP at mole fractions 0.1 (blue), 0.2 (black), 0.3 (red), and 0.4 (green). b-d Under anaerobic conditions at mole fractions 0.1 (b), 0.2 (c), and 0.3 (d). The inset shows the current density of the peak at $-200 \mathrm{mV}$ as a function of the mole fraction DTNTA/DTP

individual redox transitions. Figure 8 shows examples obtained from the two different preparations. Slight differences in $E_{\text {ip }}$ and $\varphi$ are within experimental errors. So, these results are consistent with earlier findings.

\section{Cyclic voltammetry}

Cyclic voltammograms (CVs) were first measured under turnover conditions of the enzyme, i.e., in the presence of oxygen (Fig. 9). Electrons that are transferred to the protein are consumed for the reduction of oxygen to water in the catalytic center of the enzyme consisting of heme $a_{3}$ and $\mathrm{Cu}_{\mathrm{B}}$ (Fig. 1). This gives rise to an amplified current density measured after activation of the enzyme under aerobic conditions. Figure 9 shows $\mathrm{CVs}$ of the $\mathrm{CcO}$ in the presence of oxygen as a function of mole fraction ranging from 0.1 to 0.4 . They show peaks at -0.2 and $-0.6 \mathrm{~V}$, which were attributed to the repeated electron and proton transfer due to multiple turnover of the enzyme [7]. The current density of the ET peak plotted as a function of mixing ratio shows a maximum at a mole fraction of 0.2 (see inset of Fig. 9). These results indicate that the optimum packing density for $\mathrm{CcO}$ is attained at a mole fraction of chelator molecules of 0.2 .

Finally, CVs of the same samples were recorded at different scan rates under anaerobic conditions for molar fractions of $0.1,0.2$, and 0.3 (Fig. 10a-c). At the mole fraction of 0.2 , a single peak at $-0.2 \mathrm{~V}$ appears in the reductive and oxidative branch of the $\mathrm{CV}$, as found in earlier studies [7], whereas only a cathodic peak appears at 
the other mole fractions. These peaks had been shown earlier on the basis of spectroelectrochemical studies using Raman and IR to represent the direct ET to the four centers $\mathrm{Cu}_{\mathrm{A}}$, heme a, heme $\mathrm{a}_{3}$, and $\mathrm{Cu}_{\mathrm{B}}[7,18]$.
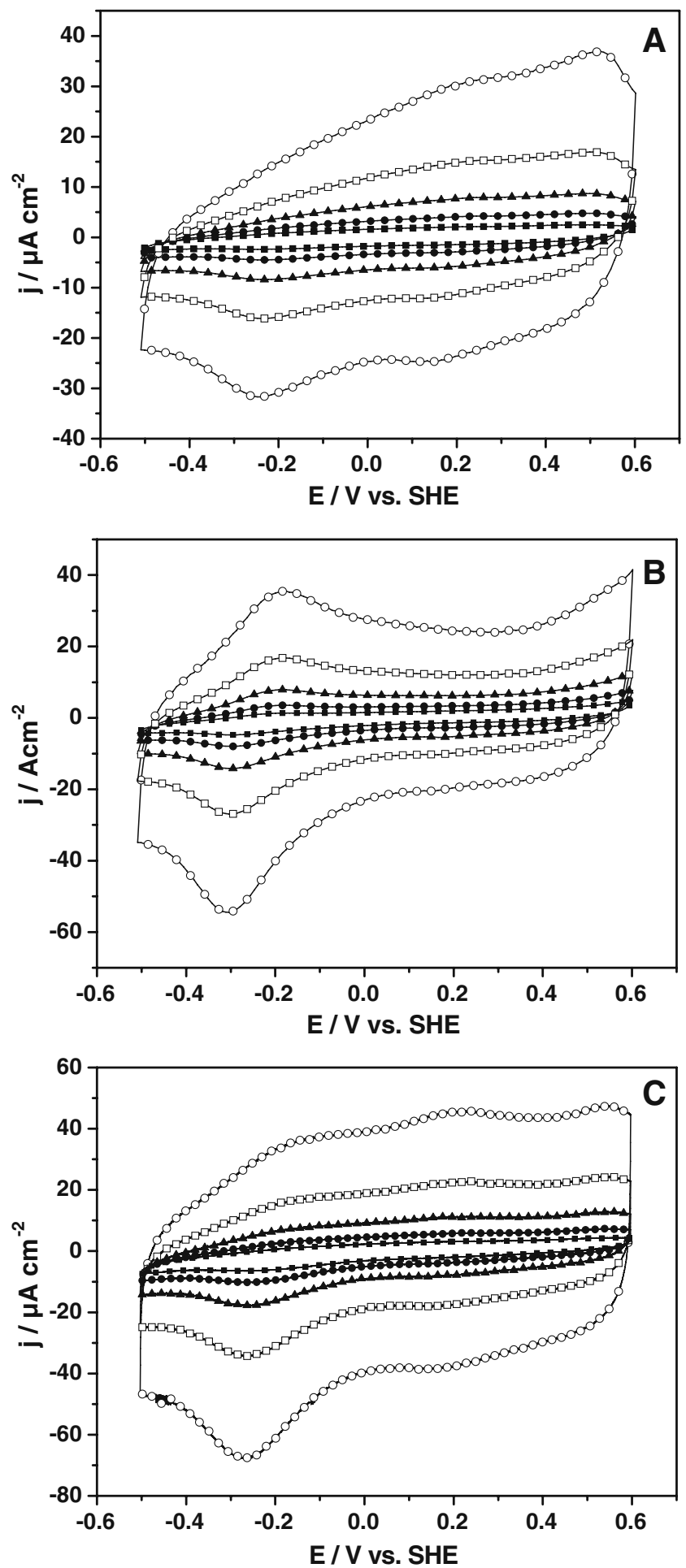

Fig. $10 \mathrm{CVs}$ under anaerobic conditions at mole fractions 0.1 (a), 0.2 (b), and 0.3 (c). Measured at scan rates of $50 \mathrm{mV} / \mathrm{s}$ (solid squares), 100 (solid circles), 200 (solid triangles), 400 (open squares), and $800 \mathrm{mV} / \mathrm{s}$ (open circles)
Table 2 Parameter values fitted to the reductive peak of CVs shown in Fig. 10 using the sequential ET model

\begin{tabular}{llll}
\hline Mole fraction & 0.1 & 0.2 & 0.3 \\
\hline$\Gamma_{\mathrm{p}} /\left(\mathrm{pMol} \mathrm{cm} \mathrm{cm}^{-2}\right)$ & $5.122 \pm 0.04$ & $5.947 \pm 0.03$ & $17.26 \pm 0.13$ \\
$E_{\mathrm{o}, 1} / \mathrm{mV}$ & $-238.7 \pm 1.7$ & $-276.4 \pm 0.9$ & $-245.1 \pm 1.5$ \\
$k_{\mathrm{e}, 1} / \mathrm{s}^{-1}$ & $121 \pm 15$ & $277 \pm 14$ & $65 \pm 5$ \\
$E_{\mathrm{o}, 2} / \mathrm{mV}$ & $-303.2 \pm 1.6$ & $-311.4 \pm 1.2$ & $-315.6 \pm 1.7$ \\
$k_{1,2} / \mathrm{s}^{-1}$ & 10,000 & 10,000 & 10,000 \\
$E_{\mathrm{o}, 3} / \mathrm{mV}$ & $-103.5 \pm 2.9$ & $-221.3 \pm 1.4$ & $-109.7 \pm 2.9$ \\
$k_{2,3} / \mathrm{s}^{-1}$ & 10,000 & 10,000 & 10,000 \\
$E_{\mathrm{o}, 4} / \mathrm{mV}$ & $-185.5 \pm 2.4$ & $-328.4 \pm 1.3$ & $-198.7 \pm 2.5$ \\
$k_{3,4} / \mathrm{s}^{-1}$ & 10,000 & 10,000 & 10,000
\end{tabular}

The uncertainty of fitted values based on variance analysis [16] is indicated by \pm ; values without \pm were fixed in the fitting procedure

Analysis of cyclic voltammograms

When analyzing the CVs in terms of the models, it was found that reliable and representative values for the fitted parameters are only obtained if both reductive and oxidative peaks are included [9]. As is evident from Fig. 10, this is only the case for the electrode modified with DTNTA mixed with a mole fraction of 0.2 . These CVs could be successfully analyzed by means of the sequential ET model but not with the independent ET model. Hence, we concluded that electron transfer to and within the $\mathrm{CcO}$ in a ptBLM most likely follows the sequential pathway [9], which is equivalent to ET from the genuine electron donor of $\mathrm{CcO}$, i.e., cytochrome c (cf. Fig. 1).

The reductive peaks of all CVs shown in Fig. 10 were then analyzed with the model of sequential ET. The analysis with reductive and oxidative peaks simultaneously revealed that the electron exchange reactions are so much faster than electron uptake that they cannot be resolved [9]. Therefore, a large and fixed value $\left(10,000 \mathrm{~s}^{-1}\right)$ was assigned to the pertinent rate constants $k_{i, i+i}$ (cf. Fig. 3a). The values of fitted parameters thus obtained are listed in Table 2 . Since only reductive peaks were included, the data for $E_{\mathrm{o}, i}$ are merely indicative; however, those for the surface concentration of $\mathrm{CcO}, \Gamma_{\mathrm{p}}$, and for the electrochemical rate constant, $k_{e, 1}$, were found to be reliable when compared to the result of the analysis with both peaks.

The $\Gamma_{\mathrm{p}}$ values found for the electrodes modified with a mole fraction of 0.1 and 0.2 are comparable to the surface concentration $\left(6 \mathrm{pMol} / \mathrm{cm}^{2}\right)$ calculated by means of the dimensions of the $\mathrm{CcO}$ molecule for a monolayer of the protein closely packed on the air/water interface of a Langmuir trough. The $\Gamma_{p}$ value found for the mole fraction 0.3 is much too high, which is most likely due to an insufficient base line correction of these particular CVs. The $k_{e, 1}$ values clearly depend on the mole fraction, with an 
optimum at 0.2 , which definitely shows that ET is affected by the surface concentration of chelator molecules. This is in line with results of an earlier investigation on the effect of packing density for in situ functionalized surfaces [8].

\section{Conclusion}

This investigation illustrates how a particular surface architecture can be designed for a protein to facilitate direct electron transfer from an electrode. This holds even if the protein is preoriented by a specific linker. Electron transfer to $\mathrm{CcO}$ immobilized using a very similar strategy had been shown to be extremely slow $\left(0.002 \mathrm{~s}^{-1}\right)$ and not even sensitive to the orientation of the his-tag [21]. In our case, electron transfer rates to the first electron acceptor are well within the range known for other proteins [1-3]. Packing density has proved the most decisive parameter. It had to be controlled in relatively low margins, made easier by chelator molecules prepared ex situ. The linker even in the extended conformation seems to be effective for a relatively fast ET. An additional benefit of this methodology is the larger distance of the protein from the surface, thus allowing for a larger submembrane space and a larger flexibility of the $\beta$-sheet structure that extends into the aqueous phase. Flexibility seems to be of general significance for an effective ET, particularly for large membrane proteins such as the $\mathrm{CcO}$. Potentiometric titrations followed by FTIR had shown substantial conformational changes of the protein backbone of $\alpha$-helices and $\beta$-sheets during electrochemical reduction and oxidation. We concluded that the protein may undergo changes of helix geometry or strain on reduction [18]. A too high packing density would most likely prohibit such an effect. In summary, the optimum packing density was achieved on the basis of a monolayer of DTNTA mixed with DTP at a mole fraction of 0.2 .

Open Access This article is distributed under the terms of the Creative Commons Attribution Noncommercial License which permits any noncommercial use, distribution, and reproduction in any medium, provided the original author(s) and source are credited.

\section{References}

1. Armstrong FA (2002) Protein film voltammetry: revealing the mechanisms of biological oxidation and reduction. Russ $\mathrm{J}$ Electrochem 38:49-62

2. Armstrong FA (2002) Insights from protein film voltammetry into reactions of complex biological electron-transfer reactions. J Chem Soc, Dalton Trans 5:661-671
3. Jeuken LJC, Jones AK, Chapman SK, Cecchini G, Armstrong FA (2002) Electron-transfer mechanisms through biological redox chains in multicenter enzymes. J Am Chem Soc 124:5702-5713

4. Baymann F, Barlow NL, Aubert C, Schoepp-Cothenet B, Leroy G, Armstrong FA (2003) Voltammetry of a 'protein on a rope'. Febs Lett 539:91-94

5. Kroger D, Liley M, Schiweck W, Skerra A, Vogel H (1999) Immobilization of histidine-tagged proteins on gold surfaces using chelator thioalkanes. Biosensors \& Bioelectronics 14:155-161

6. Giess F (2004) The protein-tethered lipid bilayer: a novel mimic of the biological membrane. Biophys J 87:3213-3220

7. Friedrich MG, Robertson JW, Walz D, Knoll W, Naumann RL (2008) Electronic wiring of a multi-redox site membrane protein in a biomimetic surface architecture. Biophys J 94:3698-3705

8. Friedrich MG, Plum MA, Santonicola MG, Kirste VU, Knoll W, Ludwig B, Naumann RL (2008) In situ monitoring of the catalytic activity of cytochrome $\mathrm{C}$ oxidase in a biomimetic architecture. Biophys J 95:1500-1510

9. Schach D, Grosserueschkamp, M, Nowak C, Gennis RB, Ferguson-Miller S, Knoll W, Walz D, Naumann RLC (2009) Modelling direct electron transfer to a multi-redox center protein: cytochrome c oxidase. J Solid Electrochemistry (in press)

10. Nowak C (2009) A two-layer gold surface with improved surface-enhancement for spectro-electrochemistry using surfaceenhanced infrared absorption spectroscopy. Appl Spectrosc 63: 1068-1074

11. Walz D, Caplan SR, Scriven DRL, Mikulecky D (1995) Bioelectrochemistry: general introduction. Birkhäuser, Basel, pp 1-49

12. Nowak CLC, Schach D, Knoll W, Naumann RLC (2009) Electron transfer kinetics of cytochrome $\mathrm{c}$ in the sub-ms time regime using time-resolved SEIRAS. J Phys Chem (C) 113:2256-2262

13. Friedrich MG, Giess F, Naumann R, Knoll W, Ataka K, Heberle J, Hrabakova J, Murgida DH, Hildebrandt P (2004) Active site structure and redox processes of cytochrome c oxidase immobilised in a novel biomimetic lipid membrane on an electrode. Chem Comm (Camb) 21:2376-2377

14. Mitchell DM, Gennis RB (1995) Rapid purification of wildtype and mutant cytochrome-c-oxidase from rhodobacter-sphaeroides by Ni2+-Nta affinity-chromatography. Febs Lett 368:148-150

15. Robertson JW, Friedrich MG, Kibrom A, Knoll W, Naumann RL, Walz D (2008) Modeling ion transport in tethered bilayer lipid membranes. 1. Passive ion permeation. J Phys Chem B 112:10475-10482

16. McIntosh JEA, McIntosh RP (1980) Mathematical modelling and computers in endocrinology. Springer, Berlin

17. Ataka K, Giess F, Knoll W, Naumann R, Haber-Pohlmeier S, Richter B, Heberle J (2004) Oriented attachment and membrane reconstitution of his-tagged cytochrome $\mathrm{c}$ oxidase to a gold electrode: in situ monitoring by surface-enhanced infrared absorption spectroscopy. J Am Chem Soc 126:16199-16206

18. Nowak C, Santonicola MG, Schach D, Zhu J, Gennis RB, Baurecht D, Laredo T, Lipkowsky J, Walz D, Knoll W, Naumann RLC (2010) Conformational changes of the cytochrome c oxidase varying the redox state by electronic wiring. Langmuir (in press)

19. Stuart B (1997) Biological applications of infrared spectroscopy. Wiley, New York

20. Hesse MM, Herbert M, Zeech B (2005) Spektroskopische methoden in der organischen chemie. Georg Thieme, Stuttgart

21. Hrabakova J, Ataka K, Heberle J, Hildebrandt P, Murgida DH (2006) Long distance electron transfer in cytochrome c oxidase immobilised on electrodes. A surface enhanced resonance Raman spectroscopic study. Phys Chem Phys 8:759-766 